\title{
Updating of methodological approaches to the development and coordination of strategies of the subjects of the Russian Federation in order to implement the provisions of the Law № 172-FZ "On the strategic planning in the Russian Federation" Smirnova O. ${ }^{1}$, Bogdanova Yu. ${ }^{2}$ \\ Актуализация методических подходов к разработке и порядку согласования стратегий субъектов РФ в целях реализации положений Закона № 172-Ф3 «О стратегическом планировании в РФ» Смирнова О. О. ${ }^{1}$, Богданова Ю. Н. ${ }^{2}$
}

\author{
${ }^{1}$ Смирнова Ольга Олеговна / Smirnova Olga - доктор экономических наук, руководитель отделения; \\ ${ }^{2}$ Богданова Юлия Николаевна / Bogdanova Yиlia - кандидат технических наук, ведущий научный сотрудник, \\ Центр методологии стратегического планирования, \\ Отделение макроэкономического прогнозирования, стратегического планирования и пространственного развития, \\ Федеральное государственное бюджетное научно-исследовательское учреждение \\ «Совет по изучению производительных сил», г. Москва
}

\begin{abstract}
Аннотация: в иелях реализации приниипов стратегического планирования, определенных законом № 172 Ф3 «О стратегическом планировании в Российской Федерации», необходимо разработать и представить базовые требования к стратегиям сочиально-экономического развития субъектов Российской Федераџии, определить - какие блоки стратегии субъекта РФ коррелируются с какими блоками других стратегических документов, что позволит регламентировать последовательность согласований документов. В данной статье представлены отдельные требования, а также предложень подходы к перечням показателей основных блоков стратегии субъектов РФ.

Abstract: in order to implement the strategic planning principles as defined by the law № 172-FZ "On the strategic planning in the Russian Federation", it is necessary to develop and introduce the basic requirements for the strategy of socio-economic development of the Russian Federation, to determine - which blocks the subject of federation strategies are correlated with some units of other policy instruments that will regulate the sequence of approvals documents. This article presents some requirements, as well as suggested approaches to the list of indicators of basic units of the Russian Federation subjects of strategy.
\end{abstract}

Ключевые слова: стратегии субъектов РФ, методические подходы; иелевые индикаторы; показатели в стратегиях, реализаџия принципа согласованности, требования к стратегиям, закон «О стратегическом планировании в Российской Федерации», бюджетный прогноз, стратегия пространственного развития.

Keywords: strategy of the Russian Federation subjects, methodological approaches; target indicators; performance strategies, the implementation of the principle of consistency, the requirements to the strategies, the law "On the strategic planning in the Russian Federation", the budget forecast, spatial development strategy.

Стратегия субъекта РФ представляет собой документ, определяющий важнейшие направления и механизмы и методы развития данной территории на долгосрочный период, обеспечивающие в рассматриваемой перспективе достижение намеченных социальных и экономических целей с учётом долгосрочных приоритетов, целей и задач федеральной и муниципальной политики, а также крупных организаций [13].

В соответствии с законом от 28.06.2014 № 172-Ф3 «О стратегическом планировании в Российской Федерации» стратегия субъекта РФ разрабатывается на период, не превышающий периода, на который разрабатывается прогноз социально-экономического развития субъекта Российской Федерации на долгосрочный период, в целях определения приоритетов, целей и задач социально-экономического развития субъекта Российской Федерации, согласованных с приоритетами и целями социально-экономического развития Российской Федерации (172-Ф3, ст. 32). Стратегия субъекта РФ должна иметь инновационный социально ориентированный тип экономического развития. Подготовка Стратегии субъекта РФ должна осуществляться по результатам публичного обсуждения (общественное обсуждение проектов документов стратегического планирования) (172-Ф3, ст. 13), с учетом мотивированных предложений по социальноэкономическому развитию от муниципальных образований субъекта Российской Федерации развития и крупных организаций, затрагивающих данную территорию [4].

Нормативно-правовая база с момента вступления в силу Федерального закона от 28.06.2014 № 172-Ф3 «О стратегическом планировании в Российской Федерации» расширилась такими документами как Постановление Правительства РФ от 08.08.2015 № 823 «Об утверждении порядка разработки, корректировки, осуществления мониторинга и контроля реализации стратегии социально-экономического развития Российской Федерации» и Постановление Правительства РФ от 08.08 .2015 № 822 «Об утверждении Положения о содержании, составе, порядке разработки и корректировки стратегий социальноэкономического развития макрорегионов».

В части интересующего нас документа стратегии субъекта РФ в реализацию Федерального закона от 28.06.2014 № 172-Ф3 «О стратегическом планировании в Российской Федерации» новые требования о 
содержании, составе, порядке разработки, др. - разработаны не были. Нормативный акт, регламентирующий требования к стратегии субъектов РФ - Приказ Министра регионального развития РФ от 27 февраля 2007 г. № 14, которым утверждены «Требования к стратегии социально-экономического развития субъекта Российской Федерации» [9]. Сегодня отдельные положения Приказа в отдельных моментах утратили свою актуальность. Вместе с тем, Приказом были заложены важные элементы системы регионального планирования такие как единые требования к структуре стратегий социально-экономического развития субъектов Российской Федерации, введение системы индикативных показателей оценки деятельности органов государственной власти субъекта Российской Федерации, с установленными целевыми показателями на период первых 3 лет, др. [16] Однако, данный документ устарел и не отражает основные требования, которые предъявляются сегодня к стратегиям субъектов РФ, предъявляемые Федеральным законом от 28.06.2014 № 172-Ф3 «О стратегическом планировании в Российской Федерации».

В этой связи, в первую очередь необходимо разработать и представить требования к стратегии субъекта РФ, определить - какие блоки стратегии субъекта РФ коррелируются с какими блоками других стратегических документов, а уже потом предлагать регламентировать данную последовательность согласований [15].

Рассмотрим требования, которые предъявляются Федеральным законом от 28.06.2014 № 172 -Ф3 «О стратегическом планировании в Российской Федерации» к стратегиям социально-экономического развития субъектов РФ.

Таблица 1. Требования к стратегии социально-экономического развития субъекта Российской Федерации в соответствии с Федеральным законом от 28.06.2014 № 172-Ф3 «О стратегическом планировании в Российской Федерации»

\begin{tabular}{|c|c|}
\hline Документ & $\begin{array}{c}\text { Статья 32. Стратегия социально-экономического развития субъекта Российской } \\
\text { Федерации }\end{array}$ \\
\hline $\begin{array}{l}\text { Разрабатывается } \\
\text { (период) }\end{array}$ & $\begin{array}{c}\text { разрабатывается на период, не превышающий периода, на который разрабатывается } \\
\text { прогноз социально-экономического развития субъекта Российской Федерации на } \\
\text { долгосрочный период } \\
\end{array}$ \\
\hline $\begin{array}{l}\text { Разрабатывается на } \\
\text { основе (с учетом) }\end{array}$ & $\begin{array}{c}\text { законов субъекта и нормативных документов РФ; } \\
\text { стратегии пространственного развития РФ; } \\
\text { бюджетных прогнозов РФ и субъекта РФ на долгосрочный период }\end{array}$ \\
\hline $\begin{array}{c}\text { Содержит } \\
\text { (требования к } \\
\text { структуре документа) }\end{array}$ & $\begin{array}{c}\text { оценку достигнутых целей социально-экономического развития субъекта Российской } \\
\text { Федерации; } \\
\text { приоритеты, цели, задачи и направления социально-экономической политики субъекта } \\
\text { Российской Федерации; } \\
\text { показатели достижения целей социально-экономического развития субъекта Российской } \\
\text { Федерации, сроки и этапы реализации стратегии; } \\
\text { ожидаемые результаты реализации стратегии; } \\
\text { оценку финансовых ресурсов, необходимых для реализации стратегии; } \\
\text { информацию о государственных программах субъекта Российской Федерации, } \\
\text { утверждаемых в целях реализации стратегии; } \\
\text { иные положения, определяемые законами субъекта Российской Федерации. }\end{array}$ \\
\hline $\begin{array}{l}\text { Является основой для } \\
\text { следующих } \\
\text { документов }\end{array}$ & $\begin{array}{c}\text { Статья 32, п.4, статья 37, п. 1. «Государственные программы субъекта РФ». } \\
\text { Статья 32, п.4. «Схемы территориального планирования субъекта РФ». } \\
\text { Статья 32, п. 4. «План мероприятий по реализации стратегии социально-экономического } \\
\text { развития субъекта РФ». } \\
\text { Статья 21, п. 2. «Стратегия социально-экономического развития макрорегионов». } \\
\text { Статья 35, п. } 1 \text { «Прогноз социально-экономического развития субъекта РФ на } \\
\text { среднесрочный период» }\end{array}$ \\
\hline
\end{tabular}

Таким образом, представим те документы, которые «выдают» данные и являются предшественниками для разработки стратегии субъекта Российской Федерации:

- закон субъекта Российской Федерации и нормативные документы Российской Федерации;

- стратегия пространственного развития РФ (172-ФЗ, ст. 20);

- Бюджетный прогноз Российской Федерации (172-Ф3, ст. 25);

- Бюджетный прогноз субъекта РФ на долгосрочный период (172-Ф3, ст. 34).

Теперь предлагаем обратиться к практике.

1. Стратегия пространственного развития Российской Федерации.

Утверждено Постановление Правительства РФ от 20.08.2015 N 870 «О содержании, составе, порядке разработки и утверждения стратегии пространственного развития Российской Федерации и подготавливаемых в ее составе предложений о совершенствовании системы расселения на территории Российской Федерации и приоритетных направлениях размещения производительных сил на территории Российской Федерации, осуществлении мониторинга и контроля реализации стратегии пространственного развития Российской Федерации». Однако, к разработке стратегии пространственного развития только приступили [15]. 
Вывод: в отсутствии стратегии пространственного развития, она не может на данном этапе являться основой для стратегии субъекта Российской Федерации.

2. Бюджетный прогноз Российской Федерации и Бюджетный прогноз субъекта РФ на долгосрочный период.

Утверждено Постановление Правительства РФ от 31.08.2015 N 914 «О бюджетном прогнозе Российской Федерации на долгосрочный период» (вместе с «Правилами разработки и утверждения бюджетного прогноза Российской Федерации на долгосрочный период»). Вместе с тем, Статья 170.1. Долгосрочное бюджетное планирование Бюджетного кодекса Российской Федерации в части п. 5. «Проект бюджетного прогноза (проект изменений бюджетного прогноза) Российской Федерации, субъекта Российской Федерации, муниципального образования на долгосрочный период (за исключением показателей финансового обеспечения государственных (муниципальных) программ) представляется в законодательный (представительный) орган одновременно с проектом закона (решения) о соответствующем бюджете» и в части п.6 «Бюджетный прогноз (изменения бюджетного прогноза) Российской Федерации, субъекта Российской Федерации, муниципального образования на долгосрочный период утверждается (утверждаются) соответственно Правительством Российской Федерации, высшим исполнительным органом государственной власти субъекта Российской Федерации, местной администрацией в срок, не превышающий двух месяцев со дня официального опубликования закона (решения) о соответствующем бюджете» в части субъекта Российской Федерации и муниципального образования приостановлено до 1 января 2016 года Федеральным законом от 30.09.2015 № 273-Ф3.

Вывод: в отсутствии бюджетных прогнозов разного уровня, они не могут на данном этапе являться основой для стратегии субъекта Российской Федерации.

Таким образом, сегодня не представлены те документы, с учетом которых могли бы быть разработаны стратегии субъектов Российской Федерации.

Вместе с тем, остановимся на отдельных статьях Федерального закона от 28.06.2014 № 172-Ф3 «О стратегическом планировании в Российской Федерации»:

1. Статья 40 «Цель и задачи мониторинга реализации документов стратегического планирования» говорит о том, что мониторинг осуществляется «на основе комплексной оценки основных социальноэкономических и финансовых показателей, содержащихся в документах стратегического планирования» (172-Ф3, ст. 40);

2. Статья 7. Принципы стратегического планирования, п. 11 «Принцип измеряемости целей означает, что должна быть обеспечена возможность оценки достижения целей социально-экономического развития и обеспечения национальной безопасности Российской Федерации с использованием количественных и (или) качественных целевых показателей, критериев и методов их оценки, используемых в процессе стратегического планирования». Статья 12 «Принцип соответствия показателей целям означает, что показатели, содержащиеся в документах стратегического планирования и дополнительно вводимые при их корректировке, а также при оценке эффективности деятельности федеральных органов исполнительной власти, органов исполнительной власти субъектов Российской Федерации и органов местного самоуправления, должны соответствовать целям социально-экономического развития и обеспечения национальной безопасности Российской Федерации» (172-Ф3, ст. 7).

Указанные статьи Федерального закона от 28.06.2014 № 172-Ф3 «О стратегическом планировании в Российской Федерации» говорят о единстве системы показателей, содержащихся в документах стратегического планирования [2] [11] [14] [5].

В этой связи обратим внимание на два документа, с которыми стратегии субъектов Российской Федерации опосредованно связаны и в которых определены конкретные показатели социально экономического развития Российской Федерации. Речи идет о Прогнозе социально-экономического развития Российской Федерации на долгосрочный период (172-Ф3, ст. 24) и Прогнозе социальноэкономического развития субъекта Российской Федерации на среднесрочный период (172-Ф3, ст. 35) [3].

В представленном в марте 2013 года Прогнозе долгосрочного социально-экономического развития Российской Федерации на период до 2030 года отмечено, что «прогноз социально-экономического развития Российской Федерации на период до 2030 года базируется на сценарных условиях прогноза долгосрочного социально- экономического развития Российской Федерации до 2030 года с учетом параметров прогноза социально-экономического развития Российской Федерации на 2013 год и плановый период 2014 и 2015 годов, а также подготовленных на их основе прогнозных материалах федеральных органов исполнительной власти и органов исполнительной власти субъектов Российской Федерации». Следовательно, на уровне субъектов Российской Федерации показатели были рассчитаны.

В Прогнозе долгосрочного социально-экономического развития Российской Федерации на период до 2030 года в Разделе 13 «Территориальное развитие» в разрезе федеральных округов представлены следующие показатели:

1) динамика макроэкономических показателей в инновационном сценарии (среднегодовой темп за период, \%), до 2030 г. по федеральным округам представлена по следующим показателям: ВРП; промышленное производство; конечное потребление; инвестиции в основной капитал;

2) структурная динамика в инновационном сценарии (среднегодовой темп за период 2012-2030 гг, (\%) до 2030 г. по федеральным округам представлена по следующим показателям: промышленное производство; 
добыча полезных ископаемых; обрабатывающие производства; машиностроение ; торговля; транспорт; социальные услуги.

Также представлены показатели:

- темпы роста ВРП на период до 2030 года (по вариантам), \%;

- темпы роста промышленного производства на период до 2030 года (по вариантам), \%;

- темпы роста конечного потребления на период до 2030 года (по вариантам), \%;

- темпы роста инвестиций в основной капитал на период до 2030 года (по вариантам), \%.

Второй документ - это прогноз социально - экономического развития субъекта Российской Федерации и материалы формы 2п «Основные показатели, представляемые для разработки прогноза социальноэкономического развития Российской Федерации», перечень которых ежегодно направляется Министерством экономического развития Российской Федерации в субъекты Российской Федерации.

В связи с тем, что материалы формы 2п «Основные показатели, представляемые для разработки прогноза социально-экономического развития Российской Федерации» являются единственным перечнем показателей, напрямую связанных с полным комплексом вопросов в субъекте Российской Федерации, следовательно, они могут быть использованы в качестве индикаторов, отражаемых в стратегии субъекта Российской Федерации [7] [8].

В этой связи, представим в табличном виде:

- базовые разделы стратегий субъектов Российской Федерации;

- основные разделы показателей формы 2П, где за основу взят перечень Основных показателей, представляемых для разработки прогноза социально-экономического развития Российской Федерации на 2016 год и на плановый период 2017 и 2018 годов (для субъектов Российской Федерации);

- показатели в Прогнозе долгосрочного социально-экономического развития Российской Федерации на период до 2030 года в Разделе 13 «Территориальное развитие» в разрезе федеральных округов.

Данная работа позволит нам наглядно продемонстрировать корреляцию требований к стратегиям субъектов Российской Федерации и базовым показателям прогнозов.

Таблица 2. Корреляиия между требованиями к стратегиям субъектов Российской Федерации, показателями формы $2 П$ и показателями в Прогнозе долгосрочного социально-экономического развития Российской Федерации на период до 2030 года с иелью возможности использования показателей

\begin{tabular}{|c|c|c|}
\hline $\begin{array}{c}\text { Базовые разделы стратегий } \\
\text { субъектов Российской Федерации }\end{array}$ & $\begin{array}{c}\text { Основные разделы показателей } \\
\text { формы } 2 \text { П (Перечень Основных } \\
\text { показателей, представляемых для } \\
\text { разработки прогноза социально- } \\
\text { экономического развития } \\
\text { Российской Федерации (для } \\
\text { субъектов Российской Федерации)) }\end{array}$ & $\begin{array}{c}\text { Показатели в Прогнозе } \\
\text { долгосрочного социально- } \\
\text { экономического развития } \\
\text { Российской Федерации на период до } \\
2030 \text { года в Разделе } 13 \\
\text { «Территориальное развитие» в } \\
\text { разрезе федеральных округов }\end{array}$ \\
\hline $\begin{array}{l}\text { Проблемы и приоритеты развития } \\
\text { субъекта Российской Федерации; } \\
\text { Инновационное развитие субъекта } \\
\text { Российской Федерации; } \\
\text { Социально-экономического развитие } \\
\text { субъекта Российской Федерации; } \\
\text { Образование; } \\
\text { Здравоохранение; } \\
\text { Физическая культура и спорт; } \\
\text { Культура; } \\
\text { Отрасли экономики; } \\
\text { Отрасли промышленности; } \\
\text { Агропромышленный комплекс; } \\
\text { Туристско-рекреационный комплекс; } \\
\text { Природопользование и охрана } \\
\text { окружающей среды; } \\
\text { Развитие инфраструктурных отраслей } \\
\text { субъекта Российской Федерации; } \\
\text { Транспорт; } \\
\text { Энергетика; } \\
\text { Связь и телекоммуникации; } \\
\text { Строительный комплекс; } \\
\text { Жилищно-коммунальное хозяйство; } \\
\text { Межрегиональное сотрудничество; } \\
\text { Инвестиционные проекты. }\end{array}$ & $\begin{array}{l}\text { 1. Население (Численность населения } \\
\text { (среднегодовая)) } \\
\text { 2. Производство товаров и услуг } \\
\text { 2.1. Выпуск товаров и услуг } \\
\text { 2.2. Валовой региональный продукт } \\
\text { 2.3. Промышленное производство } \\
\text { (Добыча полезных ископаемых. } \\
\text { Обрабатывающие производства. } \\
\text { Производство и распределение } \\
\text { электроэнергии, газа и воды. Индекс } \\
\text { тарифов по категориям потребителей) } \\
\text { 2.4. Сельское хозяйство } \\
\text { 2.5. Транспорт и связь } \\
\text { 2.6. Производство важнейших видов } \\
\text { продукции в натуральном выражении } \\
\text { 2.7. Строительство } \\
\text { 3. Торговля и услуги населению } \\
\text { (Распределение оборота розничной } \\
\text { торговли по формам собственности. } \\
\text { Распределение оборота розничной } \\
\text { торговли по формам торговли. } \\
\text { Структура оборота розничной } \\
\text { торговли) } \\
\text { 4. Внешнеэкономическая деятельность } \\
\text { 5. Малое и среднее } \\
\text { предпринимательство, включая } \\
\text { микропредприятия } \\
\text { 6. Инвестиции } \\
\text { 7. Консолидированный бюджет } \\
\text { субъекта Российской Федерации }\end{array}$ & $\begin{array}{l}\text { Динамика макроэкономических } \\
\text { показателей в инновационном } \\
\text { сценарии (среднегодовой темп за } \\
\text { период, \%), до } 2030 \text { г. по } \\
\text { федеральным округам по следующим } \\
\text { показателям: } \\
\text { ВРП } \\
\text { Промышленное производство } \\
\text { Конечное потребление } \\
\text { Инвестиции в основной капитал } \\
\text { Структурная динамика в } \\
\text { инновационном сценарии } \\
\text { (среднегодовой темп за период } 2012- \\
2030 \text { гг, (\%) до 2030 г. по } \\
\text { федеральным округам представлена } \\
\text { по следующим показателям: } \\
\text { Промышленное производство } \\
\text { Добыча полезных ископаемых } \\
\text { Обрабатывающие производства } \\
\text { Машиностроение } \\
\text { Торговля } \\
\text { Транспорт } \\
\text { Социальные услуги } \\
\text { Темпы роста ВРП на период до } 2030 \\
\text { года (по вариантам), \% } \\
\text { Темпы роста промышленного } \\
\text { производства на период до } 2030 \text { года } \\
\text { (по вариантам), \% }\end{array}$ \\
\hline
\end{tabular}




\begin{tabular}{|l|l|l|}
\hline & (включая местные бюджеты без учета & Темпы роста конечного потребления \\
& территориальных внебюджетных & на период до 2030 года (по \\
фондов) & вариантам), \% \\
& 8. Денежные доходы и расходы & Темпы роста инвестиций в основной \\
& населения & капитал на период до 2030 года (по \\
& 9. Труд и занятость (Распределение & вариантам), \% \\
& среднегодовой численности занятых в & \\
& экономике по формам собственности) & \\
10. Развитие социальной сферы & \\
& 11. Окружающая среда (Инвестиции в & \\
& основной капитал, направленные на & \\
& охрану окружающей среды и & \\
& рациональное использование & \\
& природных ресурсов) & \\
& 12. Туризм & \\
\hline
\end{tabular}

Основная задача стратегии субъекта РФ - обеспечение согласованности действий федеральных органов исполнительной власти и органов исполнительной власти субъекта Российской Федерации. Новая постановка задачи должна быть обеспечена системой показателей и индикаторов, отвечающих современным вызовам и угрозам, целевым задачам развития страны, отраслей и регионов [16] [12]. В этой связи основной задачей на данном этапе становления единой системы стратегического планирования становится определение методических подходов к формированию системы показателей как для всей системы стратегического планирования, так и для долгосрочного прогноза - в частности [6].

В части взаимосвязи стратегических документов, очевидно, что прогнозные документы не существуют без документов стратегических (стратегий, планов, доктрин). Это отмечено в федеральном законе от 28.06.2014 № 172-Ф3 «О стратегическом планировании в Российской Федерации», а именно в статье 3:

- п. 9) система стратегического планирования - механизм обеспечения согласованного взаимодействия участников стратегического планирования на основе принципов стратегического планирования при осуществлении разработки и реализации документов стратегического планирования, а также мониторинга и контроля реализации документов стратегического планирования в рамках целеполагания, прогнозирования, планирования и программирования с использованием нормативно-правового, информационного, научнометодического, финансового и иного ресурсного обеспечения;

- п. 1: «стратегическое планирование - деятельность участников стратегического планирования по целеполаганию, прогнозированию, планированию и программированию социально-экономического развития Российской Федерации, субъектов Российской Федерации и муниципальных образований, отраслей экономики и сфер государственного и муниципального управления, обеспечения национальной безопасности Российской Федерации, направленная на решение задач устойчивого социальноэкономического развития Российской Федерации, субъектов Российской Федерации и муниципальных образований и обеспечение национальной безопасности Российской Федерации»;

- П. 5) прогнозирование - деятельность участников стратегического планирования по разработке научно обоснованных представлений о рисках социально-экономического развития, об угрозах национальной безопасности Российской Федерации, о направлениях, результатах и показателях социально-экономического развития Российской Федерации, субъектов Российской Федерации и муниципальных образований;

- п. 6) планирование - деятельность участников стратегического планирования по разработке и реализации основных направлений деятельности Правительства Российской Федерации, планов деятельности федеральных органов исполнительной власти и иных планов в сфере социальноэкономического развития и обеспечения национальной безопасности Российской Федерации, направленная на достижение целей и приоритетов социально-экономического развития и обеспечения национальной безопасности Российской Федерации, содержащихся в документах стратегического планирования, разрабатываемых в рамках целеполагания».

В этой связи, очевидно, что нельзя отдельно рассматривать такие документы как прогнозы и стратегии. [9] [13] [10]. Базовые требования, предъявляемые к стратегическим документам в единой системе стратегического планирования, оказывают влияние на требования, структуру и порядок разработки прогнозных документов, а также на систему показателей, применяемую в тех или иных документах [1]. Следовательно, в целях определения требований к прогнозным документам, и, как следствие, к системе показателей в составе прогнозных документов необходимо определить порядок разработки основных документов стратегического планирования и их взаимоувязку.

Также в законе отмечено, что Федеральная информационная система стратегического планирования (статья 10, 172-Ф3) используется в целях «мониторинга и контроля показателей социально-экономического развития и обеспечения национальной безопасности Российской Федерации» и «мониторинга эффективности деятельности участников стратегического планирования».

Реализация подобных требований невозможна без единой системы показателей, реализуемой во всех видах документов стратегического планирования, т.е. невозможна без системы индикативного планирования [3] [2]. 
Индикативное планирование является основным рабочим инструментом по реализации целей, поставленных в стратегическом плане развития страны с учетом конкретно складывающейся экономической и социально-политической ситуации. Индикативное планирование есть процесс формирования системы параметров (индикаторов), характеризующих состояние и развитие экономики страны, соответствующие государственной социально-экономической политике, и установления мер государственного воздействия на социальные и экономические процессы с целью достижения указанных индикаторов. Индикативное государственное планирование - процесс формирования системы индикаторов (показателей) и разработка на их основе экономических мер государственного воздействия на экономические процессы для достижения установленных показателей. Индикатор - показатель, качественно определяющий количественные характеристики того или иного процесса, состояния. Может являться результатом расчетов на основании нескольких показателей [13].

Можно сделать вывод о необходимости внедрения единой системы показателей для всех видов стратегических документов, указанных в федеральном законе «О стратегическом планировании в Российской Федерации».

В целях реализации принципов стратегического планирования (172-Ф3, ст. 7): преемственности и непрерывности, сбалансированности системы стратегического планирования [13], результативности и эффективности стратегического планирования, ответственности участников стратегического планирования, прозрачности (открытости) стратегического планирования, реалистичности, ресурсной обеспеченности, измеряемости целей, соответствия показателей целям необходимо определить базовые требования к стратегиям социально-экономического развития субъектов Российской Федерации, необходимо разработать и представить требования к стратегии субъекта РФ, определить - какие блоки стратегии субъекта РФ коррелируются с какими блоками других стратегических документов, а уже потом предлагать регламентировать данную последовательность согласований [6] [9]. В данной статье представлены такие требования, а также предложены подходы к перечням показателей блоков стратегии субъектов РФ. Представлены базовые разделы стратегий субъектов Российской Федерации и требования к содержимому данных разделов. Вместе с тем, данные требования исходили из того, что сегодня уже существуют нормативно зарегламентированные показатели - показателей формы 2 П (Перечень Основных показателей, представляемых для разработки прогноза социально-экономического развития Российской Федерации (для субъектов Российской Федерации)) и показатели в Прогнозе долгосрочного социально - экономического развития Российской Федерации на период до 2030 года в Разделе 13 «Территориальное развитие» в разрезе федеральных округов.

Сегодня в практике стратегического планирования, при разработке стратегий субъектов РФ перечень показателей являются типичными, базовыми показателями Росстата. Вместе с тем, требования закона «О стратегическом планировании в Российской Федерации» к единству системы показателей и целостности системы стратегического планирования в Российской Федерации приводят к необходимости отражения и стратегиях субъектов Российской Федерации показателей из формы 2П (Перечень Основных показателей, представляемых для разработки прогноза социально-экономического развития Российской Федерации (для субъектов Российской Федерации)) минимум по таким разделам формы 2П как:

П. 2.3. Промышленное производство (Добыча полезных ископаемых. Обрабатывающие производства. Производство и распределение электроэнергии, газа и воды. Индекс тарифов по категориям потребителей);

П. 2.4. Сельское хозяйство;

П. 2.5. Транспорт и связь;

П. 2.6. Производство важнейших видов продукции в натуральном выражении;

П. 2.7. Строительство;

П. 3. Торговля и услуги населению (Распределение оборота розничной торговли по формам собственности. Распределение оборота розничной торговли по формам торговли. Структура оборота розничной торговли);

П. 4. Внешнеэкономическая деятельность;

П. 5. Малое и среднее предпринимательство, включая микропредприятия;

П. 6. Инвестиции.

Вместе с тем, данные показатели в целях согласованности и взаимоувязки, должны быть отражены в отраслевых стратегиях с детализацией в региональном разрезе.

При указанном подходе транспарентности показателей, показатели основных стратегических документов должны быть статистически наблюдаемы и постоянны из года в год в целях возможности ведения мониторинга реализации документов. В первую очередь это касается документа с максимальным перечнем показателей для региона - это форма 2П (Перечень Основных показателей, представляемых для разработки прогноза социально-экономического развития Российской Федерации (для субъектов Российской Федерации)).

\section{Лumepamypa}


1. Адамеску А. А., Смирнова О.О. Укрупнение регионов как модель новой экономической политики России // МИР (Модернизация. Инновации. Развитие), 2016. Т. 7. № 2 (26). С. 84-89.

2. Богданова Ю.Н., Прохоров В.Н., Симонова Ю.В. К вопросу обоснования базовых показателей социально-экономического развития в целях реализации закона № 172-Ф3 «О стратегическом планировании в РФ»// NovaInfo.Ru, 2016. Т. 2. № 43. С. 202-212.

3. Богданова Ю. Н., Прохоров В. Н., Симонова Ю. В. Стратегическое планирование - 2016: решение задач вчерашнего дня // NovaInfo.Ru (Электронный журнал.), 2016 г. № 44-4. Режим доступа: http://novainfo.ru/article/5651/ (дата обращения 07.11.2016).

4. Богданова Ю. Н., Смирнова О.О. Дорожная карта разработки базовых документов стратегического планирования и прогнозирования в реализацию федерального закона № 172-Ф3 «О стратегическом планировании в Российской Федерации» // Сборник. Материалы ежегодного форума молодых стратегов. М. Издательство МНЭПУ, 2015. Т. 1. С. 45-83.

5. Липина С. А. Приоритеты развития Республик Северного Кавказа. Региональная экономика: теория и практика, 2008. № 16. С. 3-9.

6. Прохоров В.Н., Смирнова О.О. Математический инструментарий для системы государственного стратегического планирований России. // «European science», 2015. № 8 (9). С. 73-76.

7. Симонова Ю. В., Смирнова О. О. Стратегии развития госкорпораций - локомотивы планового роста развития регионов и обеспечения экономической безопасности России // МИР (Модернизация. Инновации. Развитие), 2015. Т. 6. № 2. Часть 2. С. 77-82.

8. Симонова Ю. В. Роль государственных компаний в стратегическом планировании внедрения инноваций в госсекторе // Сборник. Материалы ежегодного форума молодых стратегов. М. Издательство МНЭПУ, 2015. T. 1. C. 96 - 107.

9. Смирнова О.О. Концептуальные основы формирования системы стратегического планирования регионального развития Российской Федерации // автореферат диссертации на соискание ученой степени доктора экономических наук. СОПС. Москва, 2012.

10. Смирнова О. О. Роль финансовых инструментов в стратегическом развитии государства. М.: Изд. МНЭПУ, 2011. $168 \mathrm{c.}$

11. Смирнова О. О. Актуальные вопросы государственного планирования или первые действия «на старте» за полгода после вступления в силу закона «О стратегическом планировании в Российской Федерации» // МИР (Модернизация. Инновации. Развитие). 2015. № 21. С. 55-58.

12. Смирнова О. О. Направления совершенствования региональной политики в Российской Федерации: новые вызовы и перезагрузка, 2009 год // Вестник МНЭПУ. 2009. Т. 2. С. 58-67.

13. Смирнова О. О. Основы стратегического планирования Российской Федерации. // Монография. М. ИД «Наука», 2013. $302 \mathrm{c}$.

14. Смирнова О.О. Прямой маркетинг - стратегия успеха в избирательных кампаниях // М., 1999. издательство Диалог-МГУ.

15. Смирнова О.О., Богданова Ю. Н., Симонова Ю. В. «Государственное стратегическое планирование. Реализация норм закона 172-Ф3 «О стратегическом планировании в Российской Федерации» // Рабочая программа учебной дисциплины. М., Издательство МНЭПУ. 24 с., 2015.

16. Смирнова О. О., Прохоров В.Н. Региональная политика как инструмент развития отечественной промышленности // Вестник МНЭПУ, 2009. № 1. С. 44-49. 